\title{
旅游扶贫重点村空间可达性分布特征 及影响因素研究
}

\author{
阴姣姣 ${ }^{1,2}$, 王晓芳 ${ }^{1,2 *}$, 贾圭炎 ${ }^{1,2}$, 李春明 ${ }^{1}$, 王 娟 ${ }^{3}$ \\ (1. 华中师范大学 地理过程分析与模拟湖北省重点实验室, 武汉 430079; \\ 2. 中国旅游研究院武汉分院, 武汉 430079; 3. 信阳师范学院, 河南 信阳 464000)
}

\begin{abstract}
摘 要: 在国家提出乡村振兴和旅游扶贫政策的大背景下,为了发挥旅游交通在区域发展中的带动作用, 为旅游扶 贫重点村建设和加快区域脱贫提供理论依据, 文章以湖北武陵山区 258 个旅游扶贫重点村为研究样本, 运用栅格 成本加权距离算法与地理加权回归模型(GWR)对其旅游交通可达性及影响因素在空间上影响程度及作用方向的 差异进行了探究。研究发现: 湖北武陵山区内旅游扶贫重点村的平均可达时间为 $1.82 \mathrm{~h}$, 区域整体可达性相对较 差, 出行成本较高; 从自然及人文 2 个视角对旅游扶贫重点村可达性的影响因子进行提取, 各个影响因子在区域上 作用大小的排序为: 距最邻近县市最短路径>高程>周边旅游资源禀赋>距河流最短距离>距周边景区最短距离>坡 度, 距河流最短距离及周边旅游资源禀赋与可达成本呈负相关关系, 其余因素均与可达成本呈正相关关系; 距周边 景区最短距离与坡度值大小的单位变化对可达成本空间差异的影响不显著。
\end{abstract}

关 键 词: 旅游扶贫重点村; 可达性; 地理加权回归(GWR); 湖北武陵山区

实施乡村振兴战略, 是对“乡村衰落”这一世界 性难题的及时响应。旅游扶贫工作的开展与旅游 扶贫重点村的设立是在乡村振兴政策执行上对传 统农村发展观念的扬弃, 同时也是优化乡村生活环 境、活化乡村旅游资源、促进农民脱贫致富的重要 途径。山区乡村由于地理特征上的封闭性、边远性 和复杂性使其在与外界联通及产业经济发展方面 较为落后, 因此旅游扶贫工作的最大“瓶颈” 在于交 通可达性较差, 严重阻碍了乡村旅游的发展。湖北 武陵山区作为湖北省多民族地区、集中连片特困区 和西部大开发的前沿地带, 具有良好的旅游资源基 础, 是偏远山区旅游扶贫重点村开发建设的典型代 表。“要想富、先修路”, 在贫困山区迎来旅游业发展 的重要契机下,交通问题的解决应放在首位。

可达性的概念最早由 Hansen(1959) 提出, 国外
学者从客观可达性(Bartlomiej et al, 2018)和感知可 达性(Lättman et al, 2018) 2 个视角展开了丰富的研 究, 根据研究对象的适用性及可达性概念界定的不 同在研究内容和方法上不断创新(Kwan et al, 2003; Mario et al, 2014; Merlin et al, 2018)。在旅游可达 性方面, 国内研究主要关注的焦点有: 交通网络结 构变迁对旅游地可达性空间格局的影响(蒋海兵 等, 2014; 穆成林等, 2015)、不同空间尺度下旅游景 区可达性评价的实证研究(缪理玲等, 2015; 潘竟虎 等, 2018)、可达性演变与区域旅游经济发展关系研 究(王武林等, 2015; 赵金金等, 2016; 马红等, 2018) 及与其他领域交叉的影响研究(曹芳东等, 2012; 吴 文佳等, 2014; 王兆峰等, 2016)等方面。具体到乡 村及贫困山区旅游地交通可达性, 现有的研究方法 主要有 GIS 网络分析技术、时间成本分析法、缓冲

收稿日期: 2018-12-19; 修订日期: 2019-04-16。

基金项目: 中央高校基本科研业务费(CCNU19QN053, CCNU19TD002)。[Foundation: Fundamental Research Funds for the Central Universities, No. CCNU19QN053 and CCNU19TD002. ]

第一作者简介: 阴姣姣(1994-), 女, 河南灵宝人,博士生, 主要研究方向为旅游交通地理。E-mail: yjjtourism@163.com

*通信作者简介: 王晓芳(1980-), 女, 河南许昌人, 副教授, 主要从事旅游地理及区域开发与规划相关研究。

E-mail: wangxiaofang@mail.ccnu.edu.cn

引用格式: 阴姣姣, 王晓芳, 贾圭炎, 等. 2019. 旅游扶贫重点村空间可达性分布特征及影响因素研究 [J]. 地理科学进展, 38(12): 1865-1875. [Yin J J, Wang X F, Jia Y Y, et al. 2019. Spatial accessibility distribution characteristics and influencing factors of the tourism poverty alleviation key villages in Wuling Mountain area, Hubei Province. Progress in Geography, 38(12): 1865-1875. ] DOI: 10.18306/dlkxjz.2019.12.004 
区分析法(窦银娣等, 2015; 王建英等, 2016; 王璐 等, 2016; 宋洁华等, 2017)。在旅游地可达性的影 响因素研究方面, 张忠训等(2018)认为, 封闭的地 形、道路等级及整体经济社会发展水平是影响少数 民族地区传统村落交通可达性的直接因素; 朱否等 (2018)提出, 影响区域旅游景点空间可达性的因素 主要有旅游景点空间分布、交通路网结构的区域差 异以及自然和人文环境; 王芗芗等(2018)探究交通 成本及复杂地形特征对典型贫困山区旅游景点可 达性的影响, 并提出了一种综合考虑交通因素和地 形因素的可达性评价方法; 马勇等(2017)通过研究 发现水系、山体和交通将一定程度上影响村落的可 进人性水平; 钟业喜等(2011)认为旅游景区的分布 状况及路网状况是影响江西省红色旅游景区空间 可达性的重要因素。不难发现, 现有研究一般仅将 影响因素作为可达性空间差异结果的一种解释进 行提及, 且以定性分析居多。在旅游扶贫研究方 面, 当前研究大多从当地的资源禀赋、发展模式、发 展策略以及绩效评价等方面出发, 并没有从该地区 本身的 “可进人性”这一根源问题去思考。综述国 内外已有的相关研究, 缺少对旅游扶贫重点村可达 性问题的关注, 且现有的研究大多停留在对可达成 本的计算, 对可达性空间差异原因及影响因素的挖 掘较少, 缺乏定量分析和空间计量手段的运用。

鉴于此, 本文以湖北武陵山区下辖 11 个县(市) 级行政单元的 258 个旅游扶贫重点村为研究对象, 对其可达性及影响因素进行测度和分析。以期探 明贫困地区旅游村落在进人性上存在的问题, 从而 更加科学地建设基础设施, 提高区域可进人性; 更 好地发挥旅游乘数效应、缩小区域发展差距, 促进 乡村振兴及旅游扶贫工作的进展; 同时也为中国同 类型旅游目的地建设提供理论借鉴。

\section{1 数据与方法}

\section{1 数据来源}

本文旅游扶贫重点村数据来源于原国家旅游 局、国务院扶贫办等 12 个部门和单位联合印发的 《乡村旅游扶贫工程行动方案》, 该方案中显示, 湖 北省共有 1798 个村被列人全国乡村旅游扶贫重点
村。据统计,本文所研究的湖北武陵山区所含的旅 游扶贫重点村共计 258 个 $^{(2)}$; 重要旅游景点数据来源 于湖北省文化和旅游厅(原湖北省旅游委) 官网 ${ }^{3}$, 近 年新发展非 A 级景区由本文更新补充, 共计 145 个。旅游扶贫重点村及其周边重要旅游景点的 POI 使用百度坐标拾取系统获得, 并通过 GeoSharp 软件 进行了坐标转换及纠偏。文中所涉及的行政区划、 水体、河网及公路数据主要来源于湖北省基础地理 信息数据库,结合 ArcGIS Online 所提供的最新矢 量数据获取(图 1)。坡度、高程数据来自于国家测绘 地理信息局提供的 $30 \mathrm{~m}$ 精度栅格遥感数据。空间 坐标投影选取GCS_WGS_1984, 主要数据量化和提 取均采用ArcGIS 10.4 软件完成。

\section{2 研究方法}

\subsection{1 解释变量选取与处理}

湖北武陵山区旅游扶贫重点村可达性的空间 差异是长期以来人们根据生产生活需要与山区环 境相互作用的结果, 这种结果离不开区域的自然本 底及人类活动影响。因此基于相关研究及湖北武 陵山区的实际情况, 结合变量可量化获取原则, 从 自然因素(地形、地势、河流)及人文因素(城镇发展、 景区建设、资源禀赋)两大方面的 6 个因素出发探究 研究区旅游扶贫可达性空间分异的影响因素,具体 变量选取及量化标准如表 1 所示。

其中高程、坡度、河流的获取主要通过 DEM数 据提取。人文因素中的距最邻近县市最短路径代 表了旅游中心地的集散效率与城镇发展经济社会 水平, 该变量由百度地图实时获取, 在搜索结果中 选取路程最短的方案, 共计搜索 2838 次, 获得从出 发地(旅游扶贫重点村)到目的地(县市)之间 $258 \times 11$ 的距离成本矩阵, 对矩阵进行横向最小值篮选, 最 终得到 $D_{\text {city }}$; 距周边景区的最短距离通过 ArcGIS 平 台获取。

周边旅游资源禀赋是衡量周边景区数量与级 别对旅游扶贫村可达性影响的重要指标, 考虑到非 $\mathrm{A}$ 级景点亦包含部分国家级自然保护区、国家湿地 公园等 6 类国家级重要旅游资源点,综合资源级别 及可利用程度,在孙根年等(2003)的研究基础上做 出改进,计算公式为:

$$
R=5 x_{1}+4 x_{2}+3 x_{3}+2 x_{4}+x_{5}+0.5 x_{6}
$$

\footnotetext{
(1) http://www.cpad.gov.cn/art/2016/8/11/art_1744_39.html。

(2) https://wenku.baidu.com/view/afa7b667844769eae009ede5.html。

(3) http://lyw.hubei.gov.cn/channel/lyml.html。
} 


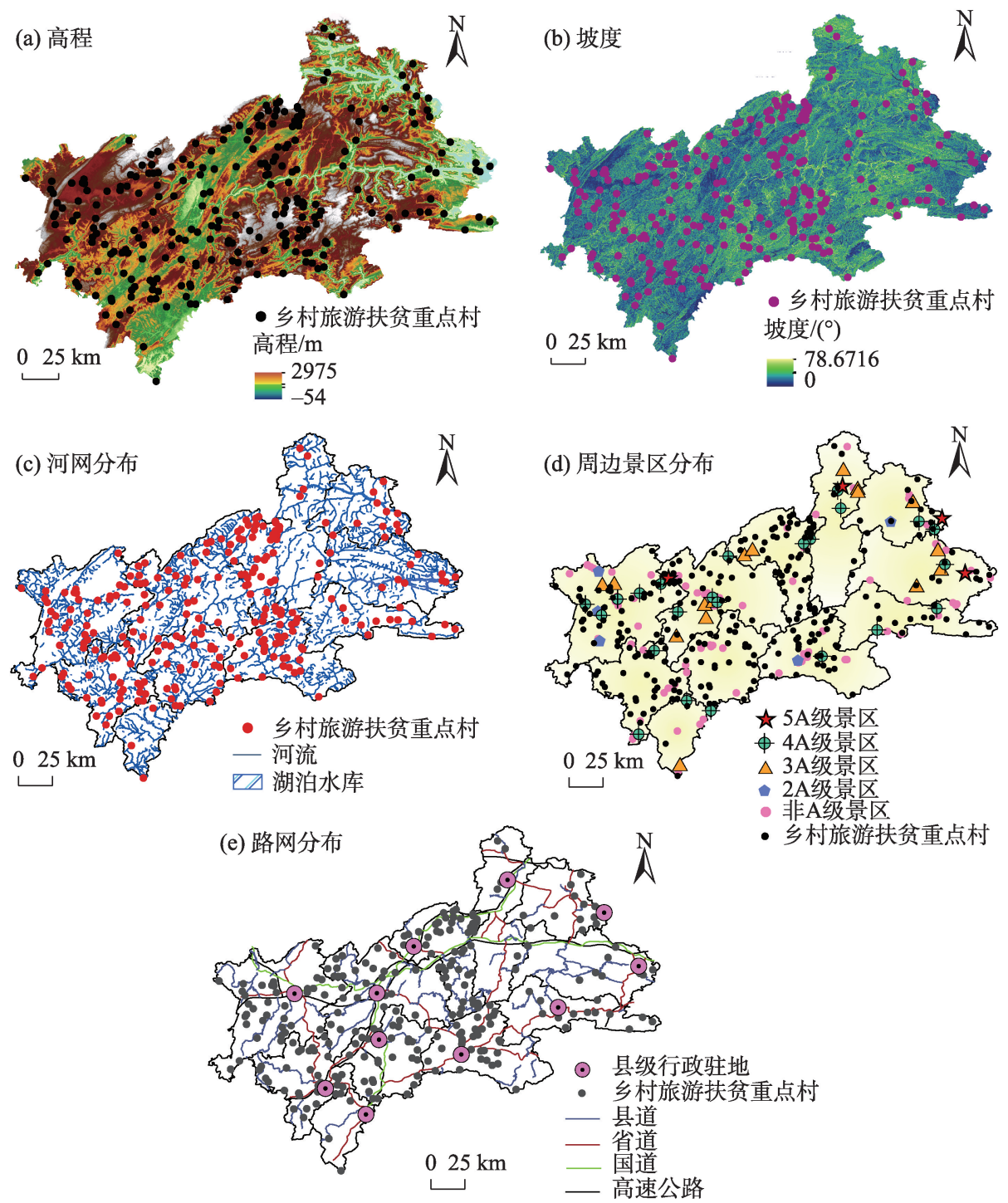

图 1 旅游扶贫重点村周边环境要素提取

Fig.1 Extraction of environmental factors around tourism poverty alleviation key villages

表 1 解释变量的选取与量化描述

Tab.1 Selection and description of explanatory variables

\begin{tabular}{|c|c|c|c|c|c|c|c|c|}
\hline 分类依据 & 影响因素 & 变量表示 & 量化标准 & 最小值 & 最大值 & 平均值 & 标准差 & 预期符号 \\
\hline \multirow[t]{3}{*}{ 自然因素 } & 地形 & $D_{\text {hei }}$ & 高程 $/ \mathrm{m}$ & 92 & 1809 & 986.25 & 186.16 & + \\
\hline & 地势 & $D_{\text {slo }}$ & 坡度/() & 1.31 & 46.43 & 15.77 & 9.26 & + \\
\hline & 河流 & $D_{\text {riv }}$ & 距河流最短距离/m & 0 & 711.26 & 108.77 & 108.43 & - \\
\hline \multirow[t]{3}{*}{ 人文因素 } & 城镇发展 & $D_{\text {city }}$ & 距最邻近县市最短路径 $/ \mathrm{km}$ & 3.3 & 131.4 & 52.44 & 28.12 & + \\
\hline & 景区建设 & $D_{\mathrm{sce}}$ & 距周边景区最短距离/m & 258.72 & 30789.61 & 8925.71 & 6194.78 & + \\
\hline & 资源禀赋 & $D_{\text {res }}$ & 周边旅游资源稁赋 & 0 & 28.5 & 4.86 & 5.07 & - \\
\hline
\end{tabular}

式中: $R$ 为旅游扶贫重点村的旅游资源禀赋得分; $x_{1} \sim x_{6}$ 分别为 $5 \mathrm{~A} 、 4 \mathrm{~A} 、 3 \mathrm{~A} 、 2 \mathrm{~A}$ 、国家级非 $\mathrm{A}$ 、非国家级 且非 $\mathrm{A}$ 级景点数; $5 、 4 、 3 、 2 、 1 、 0.5$ 分别为上述级别 景点对应的权重。对周边旅游资源禀赋的统计范
围主要以旅游扶贫重点村 $i$ 为圆心, 以 $20 \mathrm{~km}$ 为半径 构建缓冲区, 对缓冲区内的景区数量进行分类统 计。根据式(1)计算, 获得的 $R$ 即为旅游扶贫重点村 $i$ 周边的旅游资源禀赋 $\left(D_{\mathrm{res}}\right)$ 。此外, 为了消除不同 
量纲对分析结果的影响, 采用极值处理法对所有原 始数据进行归一化处理。

\subsection{2 栅格成本加权距离算法}

随着旅行距离增加, 游客需要付出更多的时 间、精力及经济成本到旅游活动中, 因此旅游者对 于目的地选择的可能性呈现一定的距离衰减规 律。依据旅游市场特征及旅游扶贫重点村同类型 旅游目的地的特质, 本文将旅游扶贫重点村的可达 性定义为: 从区域内任意一点出发, 到达距离最近 的旅游扶贫重点村所耗费的时间成本。本研究主 要针对山区内部出行, 因此以公路研究为主。借鉴 靳诚等(2010)、钟业喜等(2011)、李保超等(2016)的 研究,具体公式为:

$$
A_{o}=\min \left(M_{d} T_{o d}\right)
$$

式中: $O$ 为区域内任意一点; $T_{o d}$ 为点 $O$ 通过路网中 最短路线到达旅游扶贫重点村 $d$ 的时间成本; $M_{d}$ 为旅游扶贫重点村 $d$ 的权重, 由于仅研究交通可达 性, 故设为常数 $1 ; A_{o}$ 为区域内点 $o$ 的旅游扶贫重 点村可达性。

测算方法基于交通路网和土地利用数据, 将原 矢量底图栅格化为 $100 \mathrm{~m} \times 100 \mathrm{~m}$ 的栅格网, 共得到 3213138 个栅格, 运用 ArcGIS 软件模拟区域的可达 环境。速度设定以《中华人民共和国公路工程技术 标准(JTGB-2003)》及湖北武陵山区的实际情况为 依据(表2)。

\subsubsection{GWR 模型}

地理加权回归模型(GWR)扩展了线性回归模 型, 其回归系数 $\beta$ 不再是全局性的统一单值, 而是 随空间位置 $i$ 变化的 $\beta_{i}$, 从而可以反映解释变量对 被解释变量的影响(弹性)随空间位置的变化。地理 加权回归的实质是局部加权最小二乘法, 其中的权 为待估点所在的地理空间位置到其他各观测点的 地理空间位置之间的距离函数。GWR 数学模型形 式为 (Fotheringham et al,1996; Fotheringham et al, 2000):

$$
y_{i}=\beta_{0}\left(u_{i}, v_{i}\right)+\sum_{k=1}^{n} \beta_{k}\left(u_{i}, v_{i}\right) x_{i k}+\varepsilon_{i}
$$

式中: $y_{i}$ 为第 $i$ 个旅游扶贫重点村的可达成本; $x_{i k}$
为第 $k$ 个自变量在第 $i$ 点的值, 即 $k$ 为自变量记数; $i$ 为样本点计数; $\varepsilon_{i}$ 为残差, $n$ 为解释变量的数量; $\left(u_{i}, v_{i}\right)$ 为第 $i$ 个样本点的空间坐标; $\beta_{k}\left(u_{i}, v_{i}\right)$ 为连 续函数 $\beta_{0}\left(u_{i}, v_{i}\right)$ 在 $i$ 点的值。

GWR 模型的回归系数为:

$$
\beta_{k}\left(u_{i}, v_{i}\right)=\left(\boldsymbol{X}^{\mathrm{T}} \boldsymbol{W}\left(u_{i}, v_{i}\right) X\right)^{-1} \boldsymbol{X}^{\mathrm{T}} \boldsymbol{W}\left(u_{i}, v_{i}\right) y_{i}
$$

式中: $\boldsymbol{W}$ 为自变量矩阵; $\boldsymbol{W}\left(u_{i}, v_{i}\right)$ 表示样本点 $i$ 处 的空间权重矩阵。

由于赤池信息准则法(Akaike information criterion, AIC) 能较好地解决不同模型自由度的差异, 故 本文采用高斯函数确定权重, 以 AIC 法确定最优带 宽。则湖北武陵山区旅游扶贫重点村可达性影响 因素 GWR 模型为:

$$
\begin{aligned}
y_{i}= & \beta_{0}\left(u_{i}, v_{i}\right)+\sum_{j=1}^{k} \beta_{1}\left(u_{i}, v_{i}\right) x_{i j}\left(D_{\text {hei }}\right)+ \\
& \sum_{j=1}^{k} \beta_{2}\left(u_{i}, v_{i}\right) x_{i j}\left(D_{\text {slo }}\right)+\sum_{j=1}^{k} \beta_{3}\left(u_{i}, v_{i}\right) x_{i j}\left(D_{\text {riv }}\right)+ \\
& \sum_{j=1}^{k} \beta_{4}\left(u_{i}, v_{i}\right) x_{i j}\left(D_{\text {city }}\right)+\sum_{j=1}^{k} \beta_{5}\left(u_{i}, v_{i}\right) x_{i j}\left(D_{\text {sce }}\right)+ \\
& \sum_{j=1}^{k} \beta_{6}\left(u_{i}, v_{i}\right) x_{i j}\left(D_{\text {res }}\right)+\varepsilon_{i}
\end{aligned}
$$

式中: $y_{i}$ 为第 $i$ 个旅游扶贫重点村的可达成本; 第 $i$ 点的坐标为 $\left(u_{i}, v_{i}\right) ; \beta_{k}\left(u_{i}, v_{i}\right)$ 为第 $k$ 个解释变量的 回归系数。

\section{2 空间可达性测度}

根据公式(2), 计算旅游扶贫重点村可达性总体 空间分布格局, 可得研究区内所有旅游扶贫重点村 的平均可达时间为 $1.82 \mathrm{~h}$ 。以每 $30 \mathrm{~min}$ 为间隔(4 $7.5 \mathrm{~h}$ 这个时段由于数量少, 仅划分为 $4 \sim 5 \mathrm{~h} 、 5 \sim 7.5$ 两段)将湖北武陵山区旅游扶贫重点村的可达时间 划分为 10 个时间段,各个时间段在空间上的分布如 图 2 所示。同时计算各可达时间段的栅格面积占区 域总面积的百分比(图 3)。其中, 旅游扶贫重点村可 达时间在 $30 \mathrm{~min}$ 以内的区域占整个研究区面积的 $6.63 \% ; 120 \mathrm{~min}$ 以内的区域累计占整个研究区面积 的 $62.74 \%$, 即仍有 $37.26 \%$ 的区域旅游扶贫重点村 的可达性在 $2 \mathrm{~h}$ 以上。

表 2 湖北武陵山区不同交通方式及土地类型通行速度设计

Tab.2 Design speed for different traffic modes and land-use types in Wuling Mountain area, Hubei Province

\begin{tabular}{cccccccccc}
\hline 空间对象 & 高速公路 & 国道 & 省道 & 县道 & 乡道 & 村道 & 陆地 & 河流 & 湖泊 \\
\hline 设计速度 $/(\mathrm{km} / \mathrm{h})$ & 120 & 80 & 60 & 40 & 20 & 10 & - & - & - \\
\hline
\end{tabular}




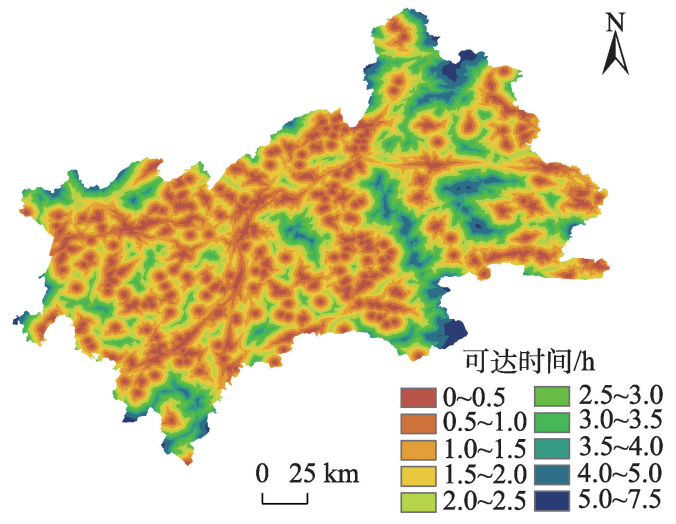

图 2 湖北武陵山区旅游扶贫重点村可达性总体格局

Fig.2 Overall pattern of accessibility of the tourism poverty alleviation key villages in Wuling

Mountain area, Hubei Province

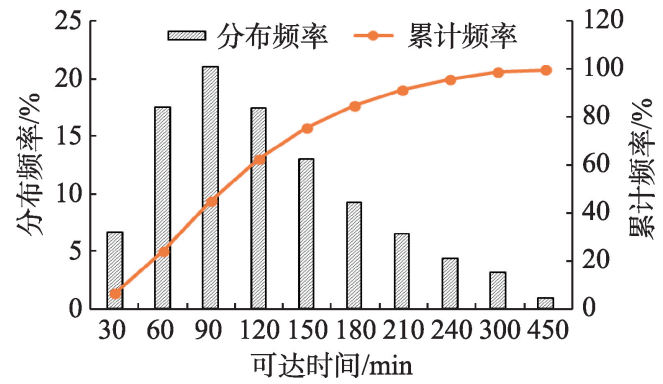

图 3 湖北武陵山区旅游扶贫重点村空间可达时间分析

Fig.3 Result of spatial access time analysis of the tourism poverty alleviation key villages in

Wuling Mountain area, Hubei Province

可达性的空间差异十分明显, 可达性较好的区 域具有明显的交通指向性,沿 G50 沪渝高速、G6911 安来高速、恩黔高速段及318 国道、209国道附近延 展; 重要城市及居民点附近可达性较高, 以县(市)级 行政单元为核心向外围辐射扩散,体现了中国山区交 通设施修建以为“人”服务为核心的重要特征; 各县市 接壤及研究区外围可达性相对较差; 可达性与旅游 扶贫村本身的分布存在较大的空间联系, 且可初步 判断在一定程度上受到山体及湖泊水系的影响。

\section{3 基于 GWR 模型的可达性影响因素} 探究

\subsection{GWR 模型回归结果分析}

在使用 GWR 模型研究旅游扶贫重点村可达性 空间差异的影响因素之前, 利用 GeoDa 095i 软件, 计算出旅游扶贫重点村可达性的全局 Moran's $I$ 指
数为 0.89232 , 表明湖北武陵山区旅游扶贫重点村 的可达性在空间上存在极强的正相关性，呈现出一 定的空间分异特征。在此基础上,首先采用全局回 归模型(OLS 模型)检验旅游扶贫重点村可达性与各 解释变量之间的平均关系。OLS 模型结果显示所 有解释变量的方差膨胀因子(VIF)在 $[1.05,1.10]$ 区 间, VIF 值均小于 10 , 因此不存在冗余的解释变 量。如表 3 所示, OLS 模型的决定系数 $R^{2}$ 和校正决 定系数调整 $R^{2}$ 分别为 0.3223 和 0.3036 , 即全局回归 模型解释了 $30.36 \%$ 旅游扶贫重点村空间可达性的 变化; 而 GWR 模型与前者相比有较大提升,模型的 解释程度达到了 $78.04 \%, \mathrm{AIC}_{c}$ 值远小于 OLS 模型, 同时模型的条件数 Cond 值均小于 30 , 证明变量间 不存在局部多重共线性的问题。综上, 确定了本文 使用GWR 模型进行分析的科学性及适用性。

通过构建 GWR 模型, 根据式(4)计算出旅游扶 贫重点村可达性各个影响因子的回归系数(表 4)。 表中的中位数在一定程度上反映了各变量对研究 区内旅游扶贫重点村可达成本的边际贡献程度, 且 所有变量回归系数的极大值、极小值符号均不相同, 说明各变量的边际效应存在方向性差异,表明了不 同空间条件下不同影响因子对旅游扶贫重点村可 达性成本的影响较为复杂。通过对 GWR 模型回归 结果的五分位值的观察可得: 高程、坡度、距最邻近 县市最短路径及距周边景区最短距离与可达成本 呈正相关关系, 而距河流最短距离及周边旅游资源 禀赋与可达成本呈负相关关系; 以上变量按贡献程 度排序为距最邻近县市最短路径>高程 $>$ 周边旅游 资源禀赋 $>$ 距河流最短距离 $>$ 距周边景区最短距离> 坡度; 距周边景区最短距离与坡度值的大小的单位 变化对可达成本空间差异的影响不显著。

\section{2 影响因素的空间异质性分析}

\subsection{1 自然因素}

(1) 地形

通过对回归系数中高程变量的系数进行可视

表 3 全局 OLS 回归与地理加权回归的模型拟合结果比较

Tab.3 Comparison of model fitting between global ordinary least squares (OLS) regression and geographically weighted regression (GWR)

\begin{tabular}{lccc}
\hline \multicolumn{1}{c}{ 模型类型 } & $R^{2}$ & 调整 $R^{2}$ & $\mathrm{AIC}_{c}$ \\
\hline Global OLS 回归 & 0.3222524 & 0.303555 & 649.435744 \\
GWR 回归 & 0.859022 & 0.780391 & 431.296964 \\
GWR 回归改进效果 & 0.5367696 & 0.476836 & 218.13878 \\
\hline
\end{tabular}


表 4 GWR 模型回归参数统计

Tab.4 Statistics of regression parameters of geographically weighted regression (GWR) model

\begin{tabular}{lccccrcc}
\hline 变量 & 极小值 & $25 \%$ 分位值 & 中位数 & $75 \%$ 分位值 & 极大值 & 均值 & 标准差 \\
\hline$D_{\text {hei }}{ }^{*}$ & -0.754 & 0.059 & 0.113 & 0.218 & 0.501 & 0.121 & 0.188 \\
$D_{\text {slo }}$ & -0.393 & -0.053 & 0.014 & 0.113 & 0.342 & 0.016 & 0.116 \\
$D_{\text {riv }}{ }^{*}$ & -0.983 & -0.103 & -0.055 & 0.031 & 0.251 & -0.060 & 0.164 \\
$D_{\text {city }}{ }^{* *}$ & -0.185 & 0.267 & 0.524 & 0.627 & 0.825 & 0.439 & 0.241 \\
$D_{\text {sce }}$ & -0.546 & -0.122 & 0.004 & 0.079 & 0.194 & -0.026 & 0.145 \\
$D_{\text {res }}{ }^{*}$ & -0.952 & -0.147 & -0.051 & 0.038 & 0.593 & -0.069 & 0.219 \\
条件数 & 1.995 & 2.973 & 3.556 & 4.361 & 10.776 & 3.975 & 1.574 \\
局部 $R^{2}$ & 0.055 & 0.295 & 0.541 & 0.669 & 0.958 & 0.495 & 0.222 \\
残差 & -1.083 & -0.170 & 0.021 & 0.211 & 1.738 & 0.021 & 0.375 \\
\hline
\end{tabular}

注:***分别表示 $P<0.05 、 P<0.01$, 表示具有显著的空间非平稳性。

化表达, 得到高程大小对旅游扶贫重点村可达性影 响的空间差异状况(图 4a)。回归系数的高回报区主 要集中在利川市的东部及南部与咸丰县交界处、宣 恩县东南部及鹤峰县的北部、长阳土家族自治县及 五峰土家族自治县境内。可见, 高程对可达成本影 响的空间差异较大, 且两者主要呈正相关关系, 如 咸丰县黄金洞乡葫芦坝村的高程为 $1303 \mathrm{~m}$, 可达成 本均值为 $493 \mathrm{~min}$; 红连村的海拔为 $1157 \mathrm{~m}$, 对应可 达成本为 $605 \mathrm{~min}$ 。但在巴东县及整个区域的西南 部地势较低的地方呈现出回归系数的低值聚集区, 甚至负值, 可见影响可达性的因子较为复杂, 高程 对村落的旅游交通可达性有一定影响, 但不存在必 然关系。总体上来讲, 较高的山地地形是致使可达 性较差的影响因素,湖北武陵山区整个区域的平均 海拔较高, 高程对旅游扶贫重点村可达性影响程度 较大,且影响程度与高程值本身的大小相对应。

(2) 地势

根据山区、丘陵的实际情况, 在具体建设时以 “不占或少占良田、好地”为原则, 道路和居民地规 划最大坡度限制有所提高, 但一般以不超过 $25^{\circ}$ 为 宜。通过对研究区内旅游扶贫村坡度值的统计和 分析发现, 有占到总体比例 $79.46 \%$ 的村子所处坡度 在 $20^{\circ} \sim 40^{\circ}$ 的范围内, 需要超出常规的道路建设成 本和工程技术支持该地公路交通的建设。如图 $4 \mathrm{~b}$, 坡度值对可达成本的影响从研究区中部向东西两 侧扩散递减,坡度值回归系数变化的弹性较小,与 其他空间变量相比对可达性差异的解释能力较为 微弱。例如, 沙道沟镇药铺村 (坡度 $46.43^{\circ}$ ) 隶属于 宣恩县, 是研究区内坡度值最大的旅游扶贫重点 村, 在图中对应出现在回归系数的高值区。因此, 地势变化对可达性影响区域相对集中, 克服坡度变
化较大的阻碍是这些地区旅游交通建设的主要 任务。

\section{(3) 河流}

区内水系以长江和清江为代表, 河流众多, 水 能蕴藏量大, 通过旅游扶贫重点村与河网水系的叠 加可知(图 4c), 旅游扶贫村的“近水性”和“沿支流分 布” 的特征显著。从旅游扶贫重点村距河流最短距 离对其交通可达性影响的回归系数结果分析(图 4c) 可知,河流因素对区域总体旅游扶贫村交通可达性 有较大的影响, 呈显著的负相关性。在研究区东部 剓归、巴东, 中部建始与西部利川等县市形成了回 归系数绝对高值及次高值的集聚分布态势。与水 源地距离的减少为居民的生产生活提供了极大的 便利, 同时高山河谷地带土壤肥沃, 是山区适宜耕 作的地区, 且山区居民点选址常以尽可能靠近生产 地为原则。但大江大河因需要跨河建桥通车, 增加 了道路交通建设的难度和成本, 在水系干流和河网 分布较为密集的地方对应出现了可达性的劣势 区。桥梁建设的不足及汛期山洪对于道路不同程 度的破坏是山区旅游扶贫重点村进人性较差的重 要原因。

\subsection{2 人文因素}

(1) 城镇发展

对旅游中心地的相关研究发现, 中国由于旅游 业发展及城镇空间结构模式存在相互作用与紧密 依存关系,旅游集散中心大多是区域内各类型的城 镇, 即传统定义上的区域中心。从旅游管理上看, 旅游中心地所管理的旅游区域一般与行政区划的 边界相一致。因此,旅游扶贫村距最邻近县市最短 路径是区域城镇建设和旅游中心地集散能力的重 要体现。如图 $4 \mathrm{~d}$, 最邻近县市最短路径与可达成本 

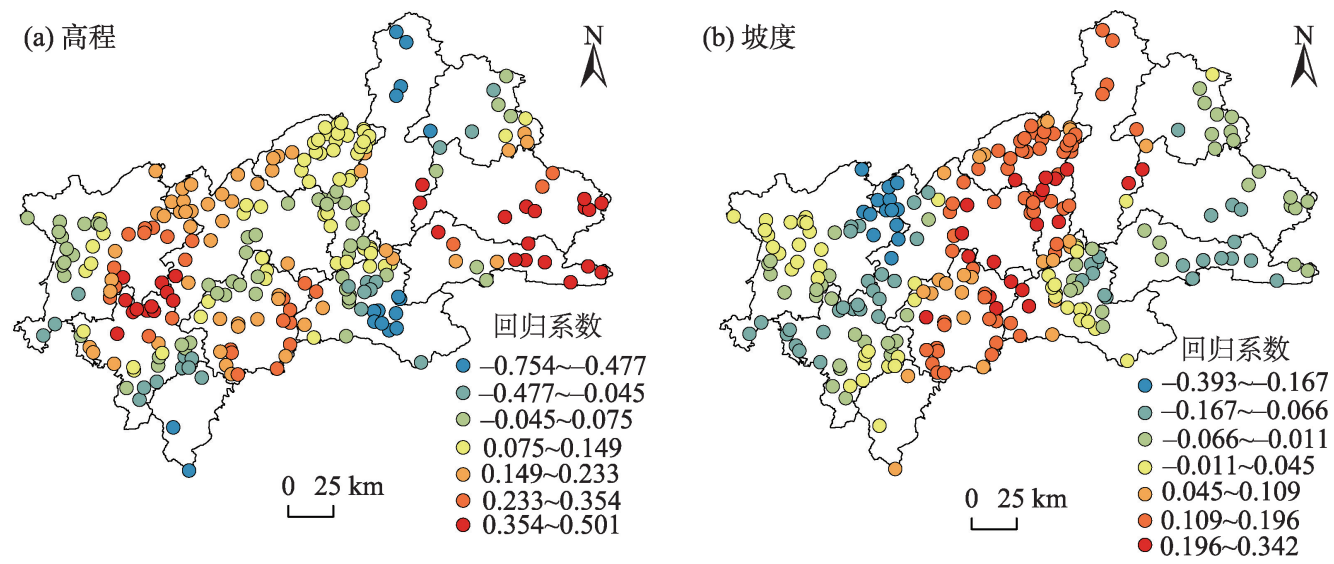

(c) 距河流最短距离

(d) 距最邻近县市最短路径
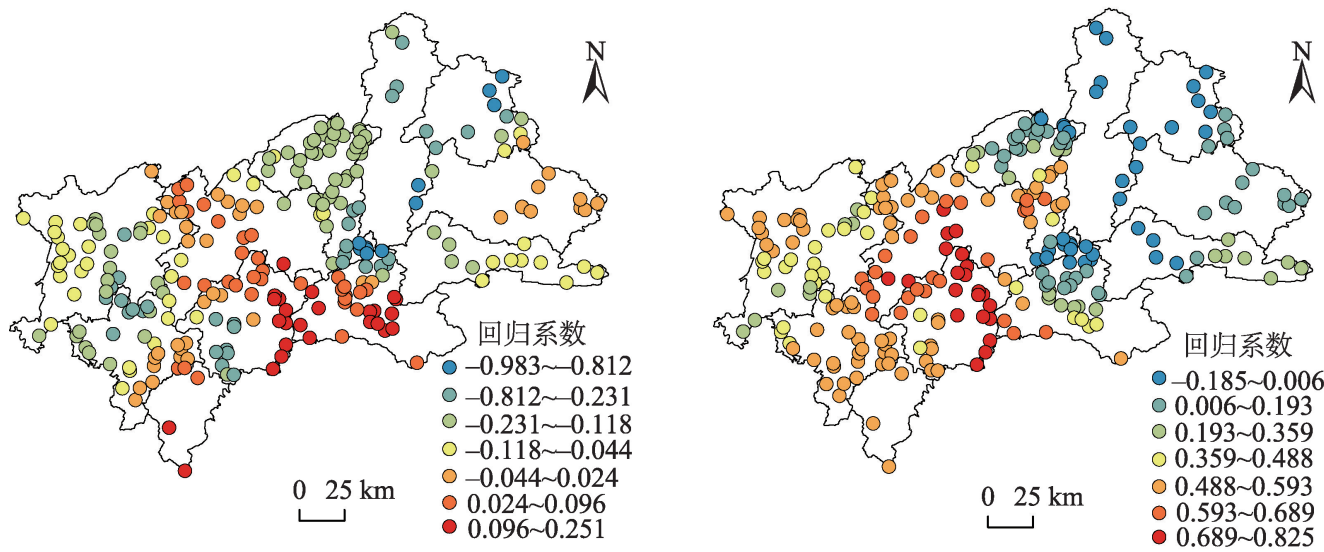

(e) 距周边景区最短距离

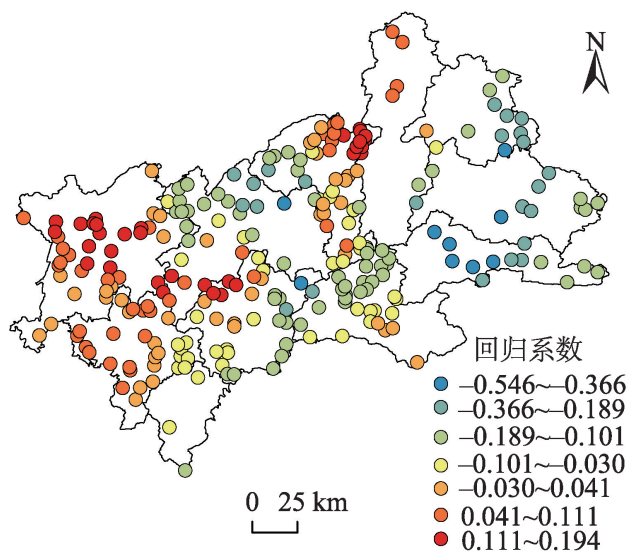

(f) 周边旅游资源禀赋

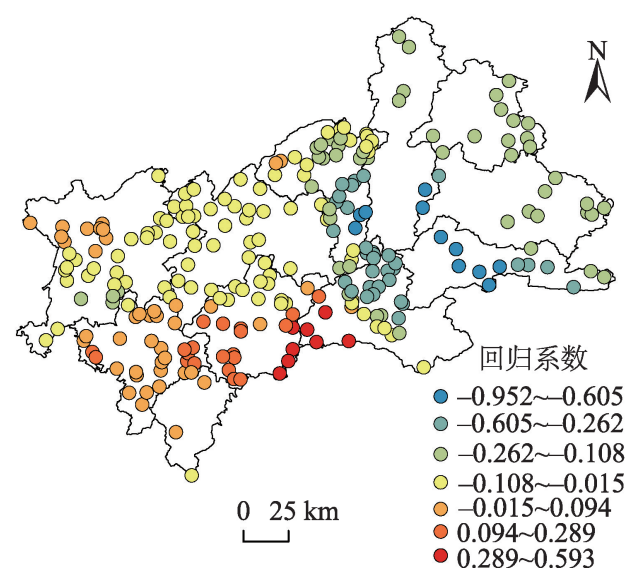

图4 GWR 回归模型各影响因素回归系数空间分布

Fig.4 Spatial distribution of regression coefficients of various influencing factors

in the geographically weighted regression (GWR) model

的变化呈显著的正相关关系,单位路径距离减少对 可达性水平的提高具有较大的边际贡献, 呈现一定 的空间溢出。回归系数的高回报区主要集中在恩 施、利川、宣恩、咸丰及来凤等 5 个县市, 说明这些区 域通过完善到达旅游中心地的路网建设, 可以较大 程度上提高旅游扶贫重点村的可达性。同时距离
旅游扶贫村道路里程最短的旅游集散地与扶贫村 隶属的行政区划中心存在部分空间错位的情况,说 明这些城镇由于发展较为滞后会流失部分过境客 源, 中心地的服务功能与集散能力较差。

(2) 景区建设

旅游扶贫重点村和旅游景区分布上存在天然 
的共生关系, 核心景区的发展建设对周边地区有一 定的辐射和带动作用。国家在旅游扶贫工作开展 过程中提倡 “景区带村” 的脱贫路子。从景区发展 来看, $\mathrm{A}$ 级景区, 特别是高级别的景区对道路建设 有较高的要求。最邻近景区对旅游扶贫重点村的 可进人性存在正向影响(图 4e), 但高值区主要集中 在恩施、利川、巴东、剓归等县市, $3 \mathrm{~A}$ 级以上的旅游 景区表现出较强的作用机制。而长阳、五峰等地虽 然有 $5 \mathrm{~A} 、 4 \mathrm{~A}$ 级旅游景区分布, 但由于数量较少, 相 对孤立, 对旅游扶贫重点村的带动作用小, 表现为 回归系数的低值区。总的来说, 最邻近景区对旅游 扶贫重点村交通影响的空间非平稳性不显著, 对旅 游可达成本的影响程度较低。

(3) 资源禀赋

以旅游扶贫重点村为圆心, 以 $20 \mathrm{~km}$ 为缓冲半 径建立基于旅游扶贫重点村的缓冲区, 发现所有的 旅游资源点几乎全被囊括在缓冲区范围内。因此 旅游扶贫重点村从整体上来说处于旅游资源条件 优越的区域, 在类型上体现为不同级别与形式的旅 游景区。通过计算可得周边旅游资源禀赋与可达 成本呈显著的负相关, 即旅游资源的优势度越高, 则旅游扶贫重点村的可达成本越低。回归系数的 绝对高值区主要集中在巴东、剓归、长阳、利川等旅 游资源禀赋得分较高的区域。从旅游活动特点及 旅游者的空间行为角度看, 游客旅行有多目的地的 特征, 旅游扶贫重点村的发展由于自身旅游资源的 局限性, 势必对周边的景区有一定的依托, 形成联 动发展效应, 旅游业资源禀赋较低而可达性较好的 区域应通过充分挖掘自身旅游资源开发潜力和区 位优势, 推动旅游扶贫重点村的脱贫致富。

\section{4 结论与启示}

本文从地理学的“人地”视角出发, 关注“以景 区带村” 的区域发展实际, 定量分析了各个因子对 旅游扶贫重点村可达性影响的空间差异状况, 是对 集中连片特困地区旅游目的地可达性问题及可达 性影响因素空间差异研究方面的一次有益探索, 同 时对科学建设基础设施、提高区域的可进入性具有 重要参考意义。

\section{1 主要研究结论}

(1) 本文利用路网及土地利用数据, 通过栅格 成本加权距离算法对区域旅游扶贫重点村的可达
性进行测算,提高了计算结果的科学性。经计算得 出, 研究区内所有旅游扶贫重点村的平均可达时间 为 $1.82 \mathrm{~h}$, 区域内大部分地区可达性相对较差, 出行 成本较高。可达性在空间上存在极强的正相关性, 呈现出一定的空间分异特征。可达性较好的区域 具有明显的交通指向性; 重要城市及居民点附近可 达性较高, 以县(市)级行政单元为核心向外围辐射 扩散,各县市接壤及研究区外围可达性相对较差; 可达性与旅游扶贫重点村本身的分布存在一定的 空间联系。

(2) 高程、坡度、距最邻近县市最短路径及距周 边景区最短距离与可达成本呈正相关关系,而距河 流最短距离及周边旅游资源禀赋与可达成本呈负 相关关系; 变量按贡献程度排序为距最邻近县市最 短路径>高程 $>$ 周边旅游资源禀赋 $>$ 距河流最短距离 $>$ 距周边景区最短距离>坡度; 距周边景区最短距离 与坡度值大小的单位变化对可达成本空间差异的 影响相对不显著。因此,旅游扶贫重点村可达性的 改善应通过提高旅游中心地的集散能力、克服高程 对道路建设的阻碍、充分利用周边旅游资源禀赋等 人为手段去提升。

(3) 此外, 由于 GWR 模型的局限与村域数据获 取的困难, 本文尚未涉及人口和产业因素对旅游扶 贫重点村可达性影响空间分异的探讨, 是今后在村 域可达性影响因素研究方面需要进一步突破和完 善的领域。

\section{2 主要启示}

(1) 目前湖北武陵山区通村公路达到了全覆 盖, 但各个等级道路之间的连通问题还需要进一步 的重视, 排查和打通断头路,完善行政区交界处路 网, 加强区域内部及区域对外连接的公路路网建设 是旅游扶贫重点村发展的重中之重; 加强和推进区 域内鹤峰、咸丰、来风、宣恩等县市低等级路网的建 设, 增加䄰归、长阳、五峰等县市连接区域西部的高 等级路网建设, 同时增加整个区域南北向公路的建 设, 从根本上缩短游客的出行时间成本; 积极建设 周边景区与旅游扶贫重点村连接的旅游公路, 将旅 游扶贫重点村作为重要的旅游节点和高等级景区 的旅游基础服务配套。

(2) 关注山区生态环境的脆弱性, 精进道路建 设技术, 克服山区山体、河流等天然因素的阻隔, 有 效规避山区滑坡及泥石流、洪涝灾害。加大交通基 础设施投人, 增加桥梁建设, 建设景观化桥梁、隧道 
及旅游通景公路, 促进运输服务与旅游融合发展。 让公路变成旅游吸引物, 带动公路沿线旅游扶贫重 点村脱贫。

(3) 结合区域实际, 进一步完善 Gunn(1988)的 目的地地带模型。加强旅游集散中心建设,优化区 域旅游空间结构。结合山区旅游发展的区域本底, 做好村级、镇级、县级——“级集散中心与集散通 道”的建设,提高人流、物流、信息流的运输效率; 进 一步完善推动旅游扶贫重点村的“连带成片”发展， 以交通路网串联优质旅游资源, 打造湖北武陵山区 的全景环线、景观长廊、精品线路和特色景点集群， 推动区域自驾旅游发展, 实现地区脱贫致富和区域 联动协调发展。

\section{参考文献(References)}

曹芳东, 黄震方, 吴江, 等. 2012. 国家级风景名胜区旅游效 率测度与区位可达性分析 [J]. 地理学报, 67(12): 16861697. [Cao F D, Huang Z F, Wu J, et al. 2012. The relationship between tourism efficiency measure and location accessibility of Chinese national scenic areas. Acta Geographica Sinica, 67(12): 1686-1697. ]

窦银娣, 彭姗姗, 李伯华, 等. 2015. 湖南省传统村落空间可 达性研究 [J]. 资源开发与市场, 31(5): 554-558, 583, 641. [Dou Y D, Peng S S, Li B H, et al. 2015. Study on spatial accessibility of traditional villages in Hunan Province. Resource Development \& Market, 31(5): 554-558, 583, 641. ]

蒋海兵, 刘建国, 蒋金亮. 2014. 高速铁路影响下的全国旅游 景点可达性研究 [J]. 旅游学刊, 29(7): 58-67. [Jiang H B, Liu J G, Jiang J L. 2014. An analysis of the accessibility of China's tourist attractions under the impact of high-speed railway. Tourism Tribune, 29(7): 58-67. ]

靳诚, 陆玉麒, 范黎丽. 2010. 基于公路网络的长江三角洲旅 游景点可达性格局研究 [J]. 自然资源学报, 25(2): 258269. [Jin C, Lu Y Q, Fan L L. 2010. Research on accessibility of scenic spots in the Yangtze River Delta based on land traffic network. Journal of Natural Resources, 25(2): 258-269. ]

李保超, 王朝辉, 李龙, 等. 2016. 高速铁路对区域内部旅游 可达性影响: 以皖南国际文化旅游示范区为例 [J]. 经济 地理, 36(9): 182-191. [Li B C, Wang C H, Li L, et al. 2016. The influence of high-speed railways on accessibility of tourism in the region: A case study of Southern Anhui International Cultural Tourism Destination. Economic Geography, 36(9): 182-191. ]

马红, 吴红, 吕顼顺, 等. 2018. 延边地区旅游经济与交通可 达性的耦合协调分析 [J]. 延边大学农学学报, 40(2): 14-
23. [Ma H, Wu H, Lv B S, et al. 2018. Analysis on the influence mechanism of transportation network for the economy level of regional tourism: A case of Yanbian Prefecture. Agricultural Science Journal of Yanbian University, 40 (2): 14-23. ]

马勇, 黄智洵. 2017. 基于 GWR 模型的长江中游城市群传统 村落空间格局及可达性探究 [J]. 人文地理, 32(4): 78-85. [Ma Y, Huang Z X. 2017. Research on spatial distribution and accessibility of the traditional villages in the urban agglomeration on the middle reaches of the Yangtze River based on GWR model. Human Geography, 32(4): 78-85. ]

缪理玲, 方朝阳, 潘彦江, 等. 2015. 井风山风景区公路网络 整体可达性分析 [J]. 经济地理, 35(3): 178-184. [Miu L L, Fang C Y, Pan Y J, et al. 2015. The entirely accessibility analysis of highway network in Jinggangshan Scenic Region. Economic Geography, 35(3): 178-184. ]

穆成林, 陆林, 黄剑锋, 等. 2015. 高铁网络下的长三角旅游 交通格局及联系研究 [J]. 经济地理, 35(12): 193-202. [Mu C L, Lu L, Huang J F, et al. 2015. Research on Yangtze River delta tourist traffic pattern and linkage under the high- speed rail network. Economic Geography, 35(12): 193-202. ]

潘竟虎, 徐柏翠. 2018. 中国国家级自然保护地的空间分布 特征与可达性 [J]. 长江流域资源与环境, 27(2): 353-362. [Pan J H, Xu B C. 2018. Spatial distribution characteristics and accessibility of protected areas in China. Resources and Environment in the Yangtze Basin, 27(2): 353-362. ]

宋洁华, 李敏纳, 蔡舒, 等. 2017. 海南交通可达性的测度与 空间分异格局分析 [J]. 地理科学, 37(10): 1507-1516. [Song J H, Li M N, Cai S, et al. 2017. The measurement and spatial differentiation pattern of traffic accessibility in Hainan. Scientia Geographic Sinica, 37(10): 1507-1516. ] 孙根年, 冯茂娥. 2003. 西部人境旅游市场竞争态与资源区 位的关系 [J]. 西北大学学报(自然科学版), 33(4): 459464. [Sun G N, Feng M E. 2003. Inbound tourism market competitive state and the relationship with resources and location factor in the west of China. Journal of Northwest University (Natural Science Edition), 33(4): 459-464. ]

王建英, 黄远水, 叶新才. 2016. 可达性及游憩压力视角下乡 村旅游景区(点)空间结构优化 [J]. 地理与地理信息科 学, 32(5): 110-114. [Wang J Y, Huang Y S, Ye X C. 2016. Layout optimization of rural tourism scenic spots based on accessibility and recreational pressure. Geography and Geo-Information Science, 32(5): 110-114. ]

王璐, 黄晓燕, 曹小曙, 等. 2016. 贫困山区不同层级可达性 及其经济效应: 以秦巴山区为例 $[\mathrm{J}]$. 经济地理, 36(1): 156-164. [Wang L, Huang X Y, Cao X S, et al. 2016. The accessibility of different scales and its impacts on econo- 
my development in poverty-stricken mountainous areas: A case study in Qinba Mountain Areas. Economic Geography, 36(1): 156-164. ]

王武林, 王妙妙, 曹小曙. 2015. 1978-2012 年武陵山区公路 通达性演化及其对经济发展的影响 [J]. 地理研究, 34 (9): 1755-1769. [Wang W L, Wang M M, Cao X S. 2015. Evolution of road accessibility and its effects on economy development in Wuling Mountain Areas from 1978 to 2012. Geographical Research, 34(9): 1755-1769. ]

王芗芗, 王英杰, 戈大专, 等. 2018. 典型贫困山区旅游景点 可达性评价方法研究 [J]. 地球信息科学学报, 20(7): 957966. [Wang Y Y, Wang Y J, Ge D Z, et al. 2018. Accessibility of scenic spots in typical poverty-stricken mountainous areas. Journal of Geo- information Science, 20(7): 957966. ]

王兆峰, 徐赛, 邓楚雄. 2016. 高速公路对武陵山区旅游城市 吸引力影响及差异 [J]. 经济地理, 36(12): 189-196. [Wang Z F, Xu S, Deng C X. 2016. Influence and differences of highway on tourism cities' attraction in Wuling Mountain area. Economic Geography, 36(12): 189-196. ] 吴文佳, 张晓平, 李媛芳. 2014. 北京市景观可达性与住宅价 格空间关联 [J]. 地理科学进展, 33(4): 488-498. [Wu W J, Zhang X P, Li Y F. 2014. Spatial correlation analysis of landscape accessibility and residential housing price in Beijing. Progress in Geography, 33(4): 488-498. ]

张忠训, 杨庆媛, 王立, 等. 2018. 少数民族地区传统村落交 通可达性分析: 以贵州省铜仁市为例 [J]. 资源科学, 40 (11): 2296-2306. [Zhang Z X, Yang Q Y, Wang L, et al. 2018. Traffic accessibility analysis of traditional villages in minority areas:A case study of Tongren City, Guizhou Province. Resources Science, 40(11): 2296-2306. ]

赵金金. 2016. 基于交通可达性的山东省旅游经济空间格局 研究 [J]. 资源开发与市场, 32(10): 1263-1268. [Zhao J J. 2016. Study on spatial structure of tourism economy based on tourism transportation accessibility in Shandong Province. Resource Development \& Market, 32(10): 12631268. ]

钟业喜, 刘影, 赖格英. 2011. 江西省红色旅游景区可达性分 析及空间结构优化研究 [J]. 江西师范大学学报(自然科
学版), 35(2): 208-212. [Zhong Y X, Liu Y, Lai G Y. 2011. The study on accessibility and spatial structures for red tourist attractions in Jiangxi Province. Journal of Jiangxi Normal University (Natural Science), 35(2): 208-212. ]

朱否, 胡静, 周葆华, 等. 2018. 区域旅游景点空间分布格局 及可达性评价: 以皖南国际文化旅游示范区为例 [J]. 经 济地理, 38(7): 190-198, 216. [Zhu L, Hu J, Zhou B H, et al. 2018. Regional tourism attractions accessibility of spatial distribution pattern and measure: A case study of Southern Anhui international cultural tourism destination. Economic Geography, 38(7): 190-198, 216. ]

Bartlomiej R, Marcin S. 2018. Major transport infrastructure investment and regional economic development: An accessibility-based approach [J]. Journal of Transport Geography, 72: 36-49.

Fotheringham A S, Brunsdon C, Charlton M E. 2000. Quantitative Geography: Perspectives on spatial data analysis [M]. London, UK: SAGE Publications.

Fotheringham A S, Charlton M E, Brunsdon A S. 1996. The geography of parameter space: An investigation into spatial non-stationary [J]. International Journal Geographical Information Systems, 10: 605-627.

Gunn C A. 1988. Vacationscape: Designing tourist regions [M]. New York, USA: Van Nostrand Reinhold.

Hansen W G. 1959. How accessibility shapes land- use [J]. Journal of American Institute of Planners, 25(2): 73-76.

Kwan M P, Murray A T, O'Kelly M E. 2003. Recent advance in accessibility research: Representation, methodology and applications [J]. Geographical Systems, 5: 129-138.

Lättman K, Olsson L E, Friman M. 2018. A new approach to accessibility: Examining perceived accessibility in contrast to objectively measured accessibility in daily travel [J]. Research in Transportation Economics, 69: 501-511.

Mario R, Antonio P, Catherine M. 2014. Walking accessibility to urban parks by children: A case study of Montreal [J]. Landscape and Urban Planning, 125: 38-47.

Merlin L A, Levine J, Grengs J. 2018. Accessibility analysis for transportation projects and plans $[\mathrm{J}]$. Transport Policy, 69: 35-48. 


\title{
Spatial accessibility distribution characteristics and influencing factors of the tourism poverty alleviation key villages in Wuling Mountain area, Hubei Province
}

\author{
YIN Jiaojiao $^{1,2}$, WANG Xiaofang ${ }^{1,2^{*}}$, JIA Yaoyan ${ }^{1,2}$, LI Chunming ${ }^{1}$, WANG Juan ${ }^{3}$ \\ (1. Key Laboratory for Geographical Process Analysis \& Simulation, Central China Normal University, Wuhan 430079, China; \\ 2. Wuhan Branch of China Tourism Academy, Wuhan 430079, China; \\ 3. Xinyang Normal University, Xinyang 464000, Henan, China)
}

\begin{abstract}
In the context of rural revitalization and poverty alleviation through tourism proposed by the state, in order to give play to the driving role of tourism transportation in regional development, it is important to provide a theoretical basis for the construction of key villages for poverty alleviation through tourism and the acceleration of regional poverty alleviation. Taking 258 tourism poverty alleviation key villages of in the Wuling Mountain area of Hubei Province as research samples, this study used the raster cost- weighted distance algorithm and the geographically weighted regression (GWR) model to explore the spatial differences in the accessibility of tourism transportation and the influence degree and direction of the influencing factors. The results show that: In the Wuling Mountain area, the average time to reach the tourism poverty alleviation key villages is 1.82 hours, the overall regional accessibility is relatively poor, and the travel cost is high. Factors affecting the accessibility of tourism poverty alleviation key villages in both the natural and social dimensions were extracted. The order of the impact of each influencing factor in the region is as follows: shortest path from the nearest county and city $>$ elevation $>$ tourism resource endowment in the surrounding area $>$ shortest distance from a river $>$ shortest distance from the surrounding scenic spot $>$ slope. The shortest distance from a river and surrounding tourism resource endowment are negatively correlated with the cost of access, while other factors are positively correlated with the cost of access. The unit change of the shortest distance from the surrounding scenic spot and the slope value has relatively insignificant influence on the spatial difference of access cost.
\end{abstract}

Keywords: tourism poverty alleviation key villages; accessibility; geographical weighted regression (GWR); Wuling Mountain area in Hubei Province 